\title{
Rehabilitación pulmonar ambulatoria en pacientes con Covid-19: un reto en épocas de pandemia
}

\section{Ambulatory pulmonary rehabilitation in patients with Covid-19: a challenge in times of pandemic}

- Joustin Ricardo Bermúdez Escallón ${ }^{1,}$, Alix Carolina Aldana Herrán², Dary Lizeth Parra Párraga², Yio Yamil Yasser Salim Torres 3 ,

(D) Jorge Mauricio Tolosa Cubillos ${ }^{4}$

\section{RESUMEN}

En el sistema pulmonar las enfermedades virales entrañan un desafío a la condición inmunológica; este es el caso del Coronavirus tipo 2 del Síndrome Respiratorio Agudo Grave o Sars-CoV-2 (en inglés, Severe Acute Respiratory Syndrome Coronavirus 2). La rehabilitación pulmonar es indispensable en todos los pacientes con infección por coronavirus 2019 (COVID-19) que han sido dados de alta, especialmente aquellos con compromiso del parénquima pulmonar; sin embargo, existen barreras que ponen a este grupo en mayor riesgo. Los servicios de rehabilitación deben implementar nuevas estrategias, que integren incluso tecnologías virtuales, para satisfacer las necesidades de los pacientes con la mayor objetividad posible; se deben utilizar, entre otras, las pruebas de función pulmonar dentro de parámetros seguros. La rehabilitación pulmonar se enfrenta al reto del paciente ambulatorio bajo las condiciones de la actual pandemia, si bien existe aún poca evidencia sobre el manejo. Considerando la necesidad de un enfoque terapéutico eficiente, este artículo de revisión expone las principales recomendaciones en rehabilitación pulmonar soportadas en evidencia reciente.

Palabras clave. Covid-19; rehabilitación de Covid-19; programa de rehabilitación pulmonar; rehabilitación respiratoria; paciente ambulatorio; Sars-CoV-2.

http://dx.doi.org/10.28957/rcmfr.v30spa10

\footnotetext{
Abstract respiratory rehabilitation; outpatient; Sars-CoV-2.

http://dx.doi.org/10.28957/rcmfr.v30spa10

In the pulmonary system, viral diseases show a challenge to the immune condition, in this case Coronavirus type 2 of Severe Acute Respiratory Syndrome or Sars-CoV-2. Pulmonary rehabilitation is essential in all patients discharged with Covid-19 as diagnosis, especially those with lung parenchymal involvement, however, there are barriers that put this group at greater risk. Rehabilitation services must implement new measures, integrating virtual technologies, to meet the needs of patients, with the greatest possible objectivity, using among others, pulmonary function tests, within safe parameters. Pulmonary rehabilitation faces the challenge of the outpatient, due to the novelty of this pandemic, there is little evidence on its management. Considering the need for an efficient therapeutic approach, this review article sets out the current pulmonary rehabilitation evidence recommendations.

Key words. Covid-19; Covid-19 rehabilitation; pulmonary rehabilitation program;
Autores:

${ }^{1}$ Residente Tercer año de Especialización Medicina Física y Rehabilitación. Universidad Militar Nueva Granada. Bogotá D.C.

${ }^{2}$ Residentes Segundo año de Especialización Medicina Física y Rehabilitación. Universidad Militar Nueva Granada. Bogotá D.C.

${ }^{3}$ Residente de Primer año de Especialización Medicina Física y Rehabilitación. Universidad Militar Nueva Granada. Bogotá D.C.

${ }^{4}$ Médico Especialista en Medicina Física y Rehabilitación. Hospital Militar Central, Docente Auxiliar Universidad Militar Nueva Granada.

Correspondencia:

Jorge Mauricio Tolosa Cubillos jorge.tolosa@unimilitar.edu.co

Recibido:

16.07.20

Aceptado:

15.09 .20

Publicación en línea:

15.09 .20

\section{Citación:}

Bermúdez Escallón JR, Aldana Herrán AC, Parra Párraga DL, Salim Torres YY, Tolosa Cubillos JM. Rehabilitación pulmonar

ambulatoria en paciente con COVID 19: un reto en épocas de pandemia. Rev Col Med Fis Rehab.

2020;30(Suplemento):130-141.

Conflictos de interés:

Ninguno declarado por los autores. 


\section{INTRODUCCIÓN}

En el contexto de las enfermedades infecciosas, las facultades evolutivas de los virus han expuesto la fragilidad de la condición inmunológica y biológica de la especie humana ${ }^{1,2}$. Sin embargo, este es un hecho que se ha visto de manera repetitiva desde épocas remotas, incluso con registros que se sobreponen a la subjetividad de los relatos y escritos de la época ${ }^{3,4}$.

El reto que cursa actualmente el mundo con el SARS-CoV-2, el sistema con mayor carga de estrés y lesiones es el sistema pulmonar ${ }^{5-7}$; a causa de la fisiopatología y el curso natural de la enfermedad es fundamental considerar las secuelas debidas a este agente infeccioso, en tanto que la rehabilitación debe enfocarse en prepararse para vencerlo de la manera más eficiente, adecuada e individualizada a fin de lograr el éxito terapéutico dentro de las metas de la Medicina Física y la Rehabilitación.

Los coronavirus son agentes infecciosos de 120-160 nm de diámetro con ácido ribonucleico (ARN) monocatenario, lo que les confiere un tamaño superior dentro de los virus. Otra de las características que les brinda la gran durabilidad de su envoltura, dada la configuración estructural glicoproteica instaurada en su cubierta bilipídica ${ }^{8}$. Estos agentes se propagan de manera clásica en distintas especies animales, como murciélagos, dromedarios y pangolines - esta última especie, fuente de alimento y medicina tradicional en Asia-, las cuales se consideran como hospederos intermedios; en ellos se han identificado dos grupos virales distintos relacionados con Sars-CoV-2, lo que sugiere que podría circular en mamíferos salvajes más de lo esperado, lo que prohíbe su caza y comercialización. Además, se ha documentado un coronavirus con un $99 \%$ de homología, con un dominio de unión al receptor idéntico al del Sars-CoV-2. Ello implica implementar una mayor vigilancia y más estudios que evalúen la patogenicidad y diversidad del coronavirus, debido al riesgo de provocar futuros brotes $2,9-11$.
El virus afecta el tracto pulmonar y en casos más graves genera Síndrome de Dificultad Respiratoria Aguda (SDRA). Los casos más conocidos fueron el Sars-1 en 2003 y el Mers (Middle East Respiratory Syndrome) en 20122,6,11. Una de las cualidades más alarmantes de estos virus es su capacidad de reproducción y su virulencia ${ }^{8}$; su número reproductivo [Ro] se estima en $2,2^{12}$, con una tasa de mortalidad variable entre países ${ }^{6,13}$.

Su transmisión usual ocurre por medio de gotas respiratorias y contacto con superficies de distintos materiales como plásticos, acero, látex, entre otros, que han sido expuestos a esta clase de virus. Asimismo, en ciertos procedimientos médicos -como intubación endotraqueal, broncoscopia, aspiración abierta, administración de tratamiento nebulizado, ventilación manual antes de la intubación, giro del paciente en decúbito prono, desconexión del ventilador, ventilación con presión positiva no invasiva, traqueostomía y reanimación cardiopulmonar- se pueden generar aerosoles. Incluso no se descarta la transmisión de aerosoles en sitios cerrados pocos ventilados, teniendo en tales casos un período de incubación promedio de 4,6 días ${ }^{1,14,15}$.

En el pulmón se desencadena una respuesta inmunológica dirigida al virus, especialmente en los alvéolos y su respectivo tejido epitelial $-y$ por tanto, en los neumocitos-, creando enlaces por medio de la señalización endógena exhibida por estos últimos 1,6,11. El Sars-CoV-2 tiene una mayor afinidad por los neumocitos tipo 2 y sus receptores de enzima convertidora de angiotensina II (ECA II); esta unión se da entre la glicoproteína de la espiga del virus y los receptores ECA II sobre los neumocitos ${ }^{16-18}$.

Dentro de la célula, por medio de endocitosis principalmente, el RNA monocatenario positivo del Sars-CoV-2 sale de su envoltura y comienza su propio mecanismo de producción proteica ribosomal, usando los organelos del huésped; en efecto, el RNA positivo viral actúa de manera directa sobre el ribosoma, éste 
lo toma, traduce esta cadena y produce RNA polimerasa ${ }^{8,16}$; esta polimerasa realizará la transcripción de RNA positivo a RNA complementario negativo. La polimerasa usa la cadena de RNA negativo para producir nuevamente cadenas de RNA positivas; estas cadenas se dirigen al retículo endoplasmático (RE) del huésped para continuar con la replicación de componentes estructurales del virus. Tanto el RNA positivo, como los productos del RE, se dirigen al aparato de Golgi, donde se terminan de ensamblar los componentes y el RNA, formando nuevas estructuras virales que serán secretadas por medio de exocitosis 19,20 . En este proceso de replicación viral intracelular, las estructuras del neumocito se ven afectadas por la liberación de sustancias y quimiotácticos inf lamatorios que crean una señalización dirigida a una respuesta inmunitaria contra el virus ${ }^{21,22}$.

Los macrófagos alveolares responden de manera directa a las citoquinas inflamatorias (IL-1, IL-6, IL-8, TNF- $\alpha$ ), al interferón, a patrones moleculares asociados al daño y a receptores Toll Like dirigidos al reconocimiento de partículas virales (principalmente la glicoproteína de la espiga del coronavirus), fagocitando el virus y presentado de esta manera las proteínas virales a las células T. Una vez reconocidas se produce una inmunidad adaptativa y estas se dirigen a las células B que producirán anticuerpos dirigidos hacia las proteínas presentadas. En este caso, se considera que la proteína viral presentada es la glicoproteína de la espiga. Este proceso de respuesta antigénica, contra el virus y los residuos derivados de los daños en las células alveolares, crea un entorno de reacción inflamatoria ${ }^{11,16,17}$ que incrementa la permeabilidad vascular y aumenta el reclutamiento celular circulante, lo que eleva la presión y, por tanto, el edema intersticial. Ello da como resultado un desequilibrio de la barrera álveolo-capilar que origina edema pulmonar. Como los neumocitos tipo II son productores de surfactante, este proceso inf lamatorio causará una labilidad estructural hacia el colapso que deriva en un déficit de la oxigenación ${ }^{2,6,11,23}$.
Así, esta cadena de eventos producirá daño pulmonar tisular, distribución anormal del líquido extracelular y edema pulmonar subsiguiente, afectando la relación ventilación/ perfusión y el intercambio gaseoso, lo que conlleva al Síndrome de Dificultad Respiratoria Aguda (SDRA) asociado a la neumonía por el virus $^{1,7}$.

Teniendo en cuenta la fisiopatología descrita, es procedente llevar a cabo la rehabilitación pulmonar que es un programa de intervención integral basado en la evaluación exhaustiva del paciente con enfermedades pulmonares crónicas, para quien se adaptan terapias de ejercicio supervisado, educación y cambio de comportamiento, diseñadas para optimizar la condición física y psicológica, contribuyendo así a la mejoría de la salud y la calidad de vida de los pacientes con dichas patologías pulmonares ${ }^{20}$. Aunque el programa de rehabilitación pulmonar está diseñado para patologías crónicas, es necesario que los pacientes infectados por el coronavirus que causa la enfermedad por coronavirus de 2019 (Covid-19), reciban intervenciones en rehabilitación pulmonar, puesto que el sistema respiratorio se ve significativamente afectado durante las etapas progresivas de neumonía leve, neumonía grave y SDRA ${ }^{21}$.

Expuestas las anteriores consideraciones, el objetivo de esta revisión de literatura es determinar la evidencia disponible acerca de las secuelas y la implementación de rehabilitación pulmonar ambulatoria en pacientes con Covid-19.

\section{METODOLOGÍA}

Se realizó una revisión no estructurada de la literatura publicada hasta el 2020 en las siguientes bases de datos bibliográficas: PubMed del Centro Nacional para la Información Biotecnológica (NCBI), Science Direct, Acces Medecine, Bireme, Ovid y Google Scholar. Los términos de búsqueda bibliográfica fueron: "pulmonar y sequelae", "Covid-19", "coronavirus, 
Sars associated", "pulmonary rehabilitation program", "respiratory rehabilitation", "out-patient pulmonary rehabilitation program", "outpatient respirator y rehabilitation", "coronavirus", "pulmonary capacity", "asymptomatic SARS 2", "radiological findings Covid-19”, "spike protein”, "Sars 2 Covid-19”, "Ace II receptors", "Sars 2 pulmonary function" y "telemedicine". A continuación, se realiza una revisión narrativa de la literatura disponible.

\section{RESULTADOS}

\section{Secuelas}

Entre las repercusiones específicas en el sistema respiratorio, especialmente en aquellos pacientes con SDRA por neumonía, se cuenta la destrucción del tejido pulmonar por el daño alveolar difuso, el cual, al cambiar su estructura y la del tejido celular circundante, consolida las membranas hialinas aumentado el grosor de la pared alveolar, lo que impedirá un intercambio gaseoso adecuado $24-26$. Una vez consolidado el daño intersticial se evidenciará en las imágenes el clásico patrón en vidrio esmerilado $1,7,24$.

Otra condición que diferencia al SarsCoV-2 de otros patógenos como el virus de la influenza, es la capacidad de daño endotelial asociado a procesos de microangiopatía, con una alta tasa de angiogénesis asociada que resulta en la pérdida de la adecuada relación ventilación/perfusión ${ }^{2,26}$, además de afectar el volumen espiratorio forzado en el primer segundo, la capacidad vital forzada, la capacidad de difusión pulmonar y la capacidad pulmonar total 27,28 . Teniendo en cuenta la fisiopatología de la enfermedad, existe la posibilidad de desarrollo de fibrosis y, en últimas, un patrón restrictivo ${ }^{29-31}$. Por ello, en pacientes con SARS la ventilación mecánica puede ser requerida para descargar la musculatura respiratoria, aunque puede inducir una rápida atrofia y debilidad profunda de esta musculatura $^{32}$.
Se considera que el $80 \%$ de la población contagiada con el Sars-CoV-2 se presenta asintomática ${ }^{33,34}$; no obstante, aún sin síntomas, existen cambios en la función y en la estructura pulmonar 28,35 .

\section{Criterios de ingreso al programa ambulato- rio de rehabilitación pulmonar}

El CDC (Centers for Disease Control and Prevention) ${ }^{36}$ estableció criterios para interrupción de las precauciones basadas en la transmisión y disposición de los pacientes con Covid-19 en entornos de atención médica.

Los criterios para ingresar a un paciente al programa de rehabilitación pulmonar ambulatorio se dividen en criterios clínicos y paraclínicos:

Clínicos: al menos un día con resolución de la fiebre (sin medicamento antipirético) y mejoría de la sintomatología respiratoria; al menos 10 días desde la aparición de los primeros síntomas.

Paraclínicos: los criterios clínicos sumados a dos pruebas PCR para Sars-CoV-2 negativas, con una diferencia mayor a 24 horas de realización.

La rehabilitación pulmonar está indicada en pacientes con condiciones especiales (adultos mayores, inmunocomprometidos, personas con movilidad limitada/inmovilidad debido a accidente cerebrovascular, etc.) y en aquellos con enfermedad pulmonar primaria (desde neumonía leve hasta SARS), aue serán atendidos mediante programas individualizados. No está indicada en pacientes asintomáticos con prueba positiva para Covid-19 o con enfermedad leve ${ }^{37}$.

Se excluyen aquellos pacientes que cursan con:

- Frecuencia cardíaca $>100$ latidos/min.

- Presión arterial <90/60 mmHg o > 140/90 mmHg. 
- Saturación de oxígeno $<90 \%$.

- Otras enfermedades no aptas para el ejercicio $^{38}$.

\section{Pruebas funcionales}

Los programas de rehabilitación pulmonar han demostrado un impacto positivo en el mejoramiento de síntomas, rendimiento en el ejercicio y calidad de vida. Estos programas usan pruebas funcionales con el fin de evidenciar los cambios y el impacto sobre la enfermedad. Claramente, por la novedad de la Covid-19, no se tienen evaluaciones específicas para este tipo de patología. Se han realizado diferentes revisiones que se enfocan en las alteraciones a largo plazo más prevalentes en pacientes que estuvieron hospitalizados o en unidad de cuidados intensivos (UCI) en las epidemias previas de Sars y Mers: fue evidente que la funcionalidad pulmonar y las alteraciones psicológicas son las alteraciones más prevalentes ${ }^{39}$.

Al no contar con evidencia actualizada sobre pruebas funcionales específicas, se siguen las recomendaciones dadas por la ATS (American Thoracic Society) para los programas de rehabilitación pulmonar en general, junto con las recomendaciones específicas para rehabilitación pulmonar en adultos con Covid-19: una historia clínica completa, examen físico, imágenes, evaluación nutricional y psicológica, tener en cuenta las escalas de tamizaje para síntomas de depresión y ansiedad (Inventario de Depresión de Beck, Escala de Ansiedad de Hamilton) o las Escalas Abreviadas de Depresión, Ansiedad y Estrés (DASS21) ${ }^{40-42}$. Así, se ha documentado el uso de las siguientes pruebas funcionales:

- Síntomas: disnea y fatiga, utilizando la escala de Borg modificada y la escala visual análoga.

- Rendimiento en el ejercicio: prueba de caminata de seis minutos, prueba de ejercicio cardiopulmonar que se dispensa en dos modalidades: la prueba incremental y la prueba de resistencia, ya sea en terreno plano, caminadora o en cicloergómetro.

- También es necesario evaluar la realización de la actividad física mendiante el Cuestionario Internacional de Actividad Física (IPAQ).

- Calidad de vida: utilizar cuestionarios genéricos como SF-36 y Saint George, que se pueden usar en el contexto de neumología aplicada ${ }^{38,43}$.

\section{Plan de rehabilitación}

Se deberán tener en cuenta las complicaciones respiratorias en los pacientes que padecieron Covid-19, dado cierto grado de deterioro y limitación funcional, incluyendo, pero no exclusivamente, disminución de la función respiratoria ${ }^{44}$.

El plan de rehabilitación pulmonar está indicado sobre todo en aquellos pacientes que han cursado con síntomas respiratorios graves o con Sars, con indicación después del alta puesto que cursan con condición física deficiente, dificultad para respirar después del esfuerzo, atrofia muscular (incluidos los músculos respiratorios, músculos del tronco y las extremidades) y trastorno de estrés postraumático. Se debe tener precaución en pacientes con hipertensión pulmonar, miocarditis, insuficiencia cardíaca congestiva, trombosis venosa profunda y fractura inestable antes de comenzar el tratamiento de rehabilitación respiratoria ${ }^{38}$.

El enfoque de rehabilitación remota es una nueva modalidad cuyo fin es promover la rehabilitación en el hogar y la comunidad después del alta; no obstante, en algunos casos graves la rehabilitación es más complicada, lo que puede conducir a dispensar procedimientos institucionales ${ }^{45}$.

Se considera que los pacientes con Covid-19, que se han recuperado físicamente y tienen dos reportes de hisopos negativos para el virus, 
están curados y no son infecciosos. Sin embargo, el virus puede persistir en la cavidad orofaríngea y las heces de un paciente hasta 15 días después de que se declare curado de Covid-19 (sin fiebre, sin síntomas respiratorios, con dos pruebas de hisopos negativos). Esto resulta preocupante en aquellos pacientes que son dados de alta en centros de rehabilitación, porque aún pueden infectar a otros pacientes o residentes. En estos casos se recomiendan 14 días adicionales en cuarentena ${ }^{46}$.

Los objetivos a corto plazo de la rehabilitación pulmonar son aliviar la disnea, la ansiedad y la depresión, mientras que a largo plazo son preservar la función del paciente al máximo, mejorar su calidad de vida y facilitar su regreso a la sociedad ${ }^{47}$. Según la guía de recomendaciones para rehabilitación pulmonar en adultos con Covid-19, desarrollada por especialistas de rehabilitación en China, el programa de rehabilitación va enfocado en primera medida a la educación del paciente: estilos de vida saludable y precauciones durante las actividades de rehabilitación respiratoria a través de folletos, videos y elementos educativos que promuevan la adherencia al programa ${ }^{38}$.

Se destaca la importancia de aumentar la capacidad aeróbica, lo cual tiene un rol preventivo y curativo contra la neumonía y/o el SDRA, mejorando las funciones pulmonares y previniendo el daño del pulmón. Ello se resume en cuatro mecanismos: 1) como profilaxis antibiótica y antimicótica mejorando la inmunidad corporal y pulmonar; 2) restaurando la elasticidad e incrementando la fuerza y resistencia de los músculos respiratorios, lo que conduce al incremento de la ventilación y la disminución del daño pulmonar; 3) mecanismo antioxidante que limita la liberación de radicales libres y el daño oxidativo; y 4) disminuyendo la tos y despejando las vías respiratorias, mejorando así la inmunidad pulmonar y produciendo modulación autonómica ${ }^{48}$.

El programa de rehabilitación pulmonar incluye:
- Ejercicios aeróbicos diseñados de forma individualizada de acuerdo con la enfermedad subyacente y la disfunción residual del paciente. Incluyen actividades como caminar, caminar rápido y trotar lentamente, con lo cual se logre entre el $60 \%$ y el $75 \%$ (y hasta $80-85$ $\%$ para algunos sujetos) de la frecuencia cardiaca máxima predicha ${ }^{38,47}$.

- Frecuencia: 3 a 5 sesiones por semana ${ }^{38}$.

- Tiempo: 20 a 30 minutos. Pacientes propensos a la fatiga deben realizar ejercicios intermitentes ${ }^{38}$.

- Intensidad: baja (<3,0 equivalentes metabólicos) ${ }^{49}$ en especial en pacientes oxígeno-requirentes, con monitoreo de signos vitales (frecuencia cardiaca, saturación de oxígeno y tensión arterial) ${ }^{44}$, con puntaje del esfuerzo percibido con la Escala de Borg Modificada entre 4 y 647 . Aumentar progresivamente en intensidad y duración.

Para el entrenamiento de fuerza progresivo ${ }^{38}$ :

- La carga de entrenamiento para cada grupo muscular objetivo es de 8 a 12 repeticiones máximas, entre 1 y 3 series, con intervalos de descanso de 2 minutos entre series. Ajustar incrementos de aproximadamente $5 \%$ a $10 \%$ por semana.

- Frecuencia de 2 a 3 sesiones/ semana durante 6 semanas ${ }^{38}$.

- El entrenamiento de equilibrio debe realizarse en pacientes con trastornos del equilibrio comórbidos e incluye: entrenamiento de equilibrio no armado y el instrumento de entrenamiento de equilibrio ${ }^{47}$.

- Ejercicios de respiración: incluyen el entrenamiento muscular inspiratorio si los músculos inspiratorios quedaron débiles en la fase pos-aguda ${ }^{38}$. El entrena- 
miento muscular respiratorio mejora la fuerza de este grupo de músculos, la capacidad de ejercicio, el grosor muscular del diafragma y la disnea ${ }^{32}$.

La respiración lenta y profunda, la expansión torácica (con elevación del hombro), la respiración diafragmática, la movilización de los músculos respiratorios, las técnicas de limpieza de las vías respiratorias (según sea necesario) y los dispositivos de presión espiratoria positiva se pueden agregar según las necesidades evaluadas ${ }^{46}$. Los protocolos de entrenamiento con dispositivo con válvula ajustada a un umbral de presión, generalmente usan cargas resistivas que oscilan entre $30 \%$ y $80 \%$ de la presión inspiratoria máxima. Se puede implementar en intervalos más cortos (30 respiraciones, 2 veces/día) ${ }^{32}$.

Un estudio prospectivo, cuasi-experimental, controlado y aleatorizado demostró diferencias estadísticamente significativas entre volumen espiratorio forzado en el primer segundo (VEF1) (L), capacidad vital forzada CVF (L), FEV1/FVC\% y capacidad de difusión de monóxido de carbono (DLCO)\% luego de implementar un programa de rehabilitación respiratoria consistente en: entrenamiento muscular respiratorio, ejercicio de tos, entrenamiento diafragmático (usando 1 a 3 kilogramos de peso en el abdomen en posición supina), ejercicio de estiramiento y ejercicios en el hogar ( 2 sesiones por semana, una vez al día por $10 \mathrm{~min})$, luego de 6 semanas $^{50}$.

La rehabilitación debe ser segura, pues si el paciente muestra saturación de oxígeno capilar periférico $(\mathrm{SpO} 2)$ menor de 88 \% o desarrolla síntomas como palpitaciones, sudoración, dolor torácico y falta de aliento, que el clínico considera inadecuados para la rehabilitación, el programa de rehabilitación se suspende ${ }^{47}$.

\section{Telemedicina en rehabilitación pulmonar}

Desde que la Covid-19 fue declarada una pandemia y una emergencia nacional, los hospitales comenzaron a clausurar los servicios de consulta externa para limitar el contacto social y cumplir con los lineamientos establecidos por el gobierno nacional, por lo que se ha promovido la implementación de la telemedicina para brindar atención a los pacientes que sufren principalmente de enfermedades crónicas ${ }^{51}$.

Se recomienda la conformación de una unidad de telemedicina para promover el alta protegida, monitorizar a los pacientes durante la cuarentena y garantizar la continuidad de la atención en rehabilitación pulmonar. La telemedicina es útil para el seguimiento remoto de los ejercicios prescritos y para monitorizar el estado de saturación de oxígeno y los parámetros cardiovasculares $^{52}$ : Es aquí donde el equipo portátil de monitorización de signos vitales ha jugado un papel importante en la medicina y en la rehabilitación de Covid-19, mostrando amplias perspectivas.

El método de rehabilitación remota se realiza sobre todo en pacientes aislados, mediante telemedicina (videos educativos, teleconsulta, cámaras web, dispositivos portátiles, aplicaciones de teléfonos móviles y realidad virtual, con herramientas desinfectables). Se espera que el trabajo en esta dirección conduzca a una nueva era de rehabilitación inteligente ${ }^{45,49}$.

\section{DISCUSIÓN}

El Sars-CoV-2 ha despertado un gran interés en la comunidad científica, especialmente la relativa a la salud, sin dejar a un lado otras ciencias y sectores que, de una u otra manera, se han visto implicados. Sin duda constituye un reto para el campo de la rehabilitación, puesto que los casos severos de enfermedad por coronavirus desencadenan Sars y dejan secuelas en el paciente, como fibrosis pulmonar, con la subsecuente enfermedad pulmonar restrictiva. Así mismo, se consideran también la estancia prolongada en cama y la ventilación mecánica, como factores que generan atrofia muscular y desacondicionamiento físico secundario. Es conocido que la rehabilitación pulmonar es indispensable en los pacientes en estado crítico, sin inestabilidad, ya sea que se encuentren en el área 
hospitalaria o en la ambulatoria. Sin embargo, aquellos que presentaron Sars asociado a comorbilidades, una vez dados de alta hospitalaria, entran a un grupo de riesgo que requiere un control y manejo integral para su adecuada rehabilitación. Estos pacientes representan un reto en época de pandemia porque, si bien se consideran no infecciosos (con dos pruebas de hisopos negativos y sin síntomas respiratorios), se ha limitado su asistencia a centros de rehabilitación. Esta recomendación puede estar sujeta a cambios de acuerdo con la evidencia científica que día a día se disponga.

Teniendo en cuenta lo anterior, los servicios de rehabilitación se han visto en la necesidad de poner en marcha nuevas medidas para garantizar el acondicionamiento físico de estos pacientes $\mathrm{y}$, por tanto, definir nuevas conductas que no solo generan una carga en el sistema de salud, sino en la estructura general de todo lo que se conocía hasta el momento, pues es necesario trabajar de forma diferente integrando nuevas tecnologías virtuales para satisfacer la necesidad de los pacientes en un ambiente seguro $^{53}$. La importancia de nuevas estrategias es palpable puesto que los sobrevivientes, sin importar la edad, desarrollan secuelas físicas y psicológicas a largo plazo que afectan su calidad de vida hasta por 5 años desde el inicio de la enfermedad; esto basados en la evidencia disponible de Sars-1 y Mers $2,54,55$. Incluso el $48 \%$ de los pacientes no regresan al trabajo un año después del alta y el $32 \%$ de los pacientes mueren dentro de los 5 años siguientes ${ }^{56}$.

En general, a los pacientes que ingresan al programa de rehabilitación pulmonar es común someterlos a pruebas de función pulmonar como la espirometría y la presión espiratoria e inspiratoria máxima; estas pruebas se encuentran dentro de las recomendaciones de la Asociación de Medicina Física y Rehabilitación de China $^{38}$. Sin embargo, al señalar directrices mundiales para prevenir el contagio, la American Thoracic Society (ATS) ${ }^{57}$ sugiere la realización de estas pruebas únicamente si son necesarias para decidir cambios en el tratamiento del paciente, debiendo llevarse a cabo bajo todas las medidas de bioseguridad; por esta razón se considera que, previamente al ingreso del programa, el riesgo no debe superar el beneficio, pudiéndose utilizar las evaluaciones ya descritas en este artículo.

El Covid-19 es una enfermedad reciente, pero con amplio pasado dados sus antecesores conocidos, que requiere más estudios, no solo desde el punto de vista etiológico, sino también desde la rehabilitación pulmonar, resaltando la importancia de disponer de mayor evidencia en el manejo integral de pacientes con esta patología.

\section{RESPONSABILIDADES ÉTICAS}

\section{Protección de personas y animales}

Los autores declaran que para esta investigación no se han realizado experimentos en seres humanos ni en animales.

\section{Confidencialidad de los datos}

Los autores declaran que han seguido los protocolos de su centro de trabajo sobre la publicación de datos de pacientes.

\section{Derecho a la privacidad y consentimiento informado}

Los autores declaran que en este artículo no aparecen datos que puedan identificar a las personas que respondieron la encuesta; así mismo, se contó con la aprobación de los encuestados para divulgar los datos.

\section{FINANCIACIÓN}

Ninguna.

\section{CONTRIBUCIÓN DE LOS AUTORES}

Todos los autores han realizado la búsqueda bibliográfica y redacción del presente artículo de forma conjunta y equitativa. 


\section{REFERENCIAS}

1. Palacios M, Santos E, Velázquez MA, León M. Covid-19, una emergencia de salud pública mundial. Rev Clínica Española [Internet]. 2020;marzo 20. Disponible en: http://doi.org/10.1016/j.rce.2020.03.001

2. Peeri NC, Shrestha N, Rahman MS, Zaki R, Tan Z, Bibi S, et al. The SARS, Mers and novel coronavirus (Covid-19) epidemics, the newest and biggest global health threats: what lessons have we learned? Int J Epidemiol [Internet]. 2020;49(3):717-726. Disponible en: http://doi.org/10.1093/ije/dyaa033

3. Guan Y, Vijaykrishna D, Bahl J, Zhu H, Wang J, Smith GJD. The emergence of pandemic influenza viruses. Protein Cell. 2010;1(1):9-13. Disponible en: http://doi.org/10.1007/s13238-010-0008-z

4. Taubenberger JK, Morens DM. 1918 Influenza: the Mother of All Pandemics. Emerg Infect Dis [Internet]. 2006;12(1):15-22. Disponible en: http://doi.org/10.3201/eid1209.050979

5. Wu D, Wu T, Liu Q, Yang Z. The Sars-CoV-2 outbreak: What we know. Int J Infect Dis [Internet]. 2020;94:44-48. Disponible en: http://doi.org/10.1016/j.ijid.2020.03.004

6. Tse GM, To K, Chan PK, Lo AW, Ng KC, Wu A, et al. Pulmonary pathological features in coronavirus associated severe acute respiratory syndrome (SARS). J Clin Pathol [Internet]. 2004;57(3):260-265. Disponible en: http://dx.doi.org/10.1136/jcp.2003.013276

7. Tian S, Hu W, Niu L, Liu H, Xu H, Xiao S-Y. Pulmonary Pathology of Early-Phase 2019 Novel Coronavirus (Covid-19) Pneumonia in Two Patients With Lung Cancer. J Thorac Oncol [Internet]. 2020;15(5):700-704. Disponible en: http://doi.org/10.1016/j.jtho.2020.02.010

8. Carroll K, Hobden JA, Miller S, Morse SA, Mietzner TA, Detrick B, et al. Jawetz, Melnick, \& Adelberg Microbiología médica. 27a. ed. México DF: McGrawHill-Interamericana; 2016. ISBN: 9786071513700

9. Fisher D, Heymann D. Q\&A: The novel coronavirus outbreak causing Covid-19. BMC Med [Internet]. 2020;18:57. Disponible en: http://doi.org/10.1186/s12916-020-01533-w

10. Han G-Z. Pangolins Harbor Sars-CoV-2-Related Coronaviruses. Trends Microbiol [Internet]. 2020;28(7):515-517. Disponible en: https://doi.org/10.1016/j.tim.2020.04.001

11. Gralinski LE, Baric RS. Molecular pathology of emerging coronavirus infections. J Pathol [Internet]. 2015;235(2):185-195. Disponible en: http://doi.wiley.com/10.1002/path.4454

12. Liu Y, Gayle AA, Wilder-Smith A, Rocklöv J. The reproductive number of Covid-19 is higher compared to SARS coronavirus. J Travel Med [Internet]. 2020;27(2):1-4. Disponible en: https://doi.org/10.1093/jtm/taaa021

13. Schellekens BP, Sourrouille D, \& World Bank. Tracking Covid-19 as Cause of Death: Global Estimates of Relative Severity [Internet]. Londres: The World Bank Group; 2020 [citado 2020 junio 13]. Reporte: JEL-I10-J11. Disponible en:

https://www.brookings.edu/wp-content/uploads/2020/05/Tracking_Covid-19_as_Cause_of_Death-Global_Estimates_of_Severity.pdf

14. Wu D, Wu T, Liu Q, Yang Z. The Sars-CoV-2 outbreak: What we know. Int J Infect Dis. 2020;94:44-48. Disponible en: http://doi.org/10.1016/j.ijid.2020.03.004

15. World Health Organization [WHO]. Modes of transmission of virus causing Covid-19?: implications for IPC precaution recommendations: scientific brief, 27 march 2020 [Internet]. 2020;marzo 27:1-3. Disponible en: https://apps.who.int/iris/handle/10665/331601

16. Li Y, Zhou W, Yang L, You R. Physiological and pathological regulation of ACE2, the SarsCoV-2 receptor. Pharmacol Res [Internet]. 2020;157:104833. Disponible en: http://doi.org/10.1016/j.phrs.2020.104833 
17. Zhang H, Penninger JM, Li Y, Zhong N, Slutsky AS. Angiotensin-converting enzyme 2 (ACE2) as a Sars-CoV-2 receptor: molecular mechanisms and potential therapeutic target. Intensive Care Med [Internet]. 2020;46(4):586-590. Disponible en: http://doi.org/10.1007/s00134-020-05985-9

18. Gheblawi M, Wang K, Viveiros A, Nguyen Q, Zhong J-C, Turner AJ, et al. Angiotensin-Converting Enzyme 2: Sars-CoV-2 Receptor and Regulator of the Renin-Angiotensin System. Circ Res [Internet]. 2020;126(10):1456-1474. Disponible en: https://doi.org/10.1161/CIRCRESAHA.120.317015

19. Chen Y, Liu Q, Guo D. Emerging coronaviruses: Genome structure, replication, and pathogenesis. J Med Virol [Internet]. 2020;92(4):418-423. Disponible en: https://doi.org/10.1002/jmv.25681

20. He J, Tao H, Yan Y, Huang S-Y, Xiao Y. Molecular Mechanism of Evolution and Human Infection with Sars-CoV-2. Viruses [Internet]. 2020;12(4):428. Disponible en: http://doi.org/10.3390/v12040428

21. Chen J, Wu H, Yu Y, Tang N. Pulmonary alveolar regrowth in an adult Covid-19 patient. medRxiv. 2020:mayo 10:20097634. Disponible en: http://doi.org/10.1101/2020.05.10.20097634

22. Bracco L. Covid-19, Type II Alveolar Cells and Surfactant. J Med-Clin Res Rev [Internet]. 2020;4(4):1-3. Disponible en: http://www.scivisionpub.com/pdfs/covid19-type-ii-alveolar-cellsand-surfactant-1137.pdf

23. Groß S, Jahn C, Cushman S, Bär C, Thum T. Sars-CoV-2 receptor ACE2-dependent implications on the cardiovascular system: From basic science to clinical implications. J Mol Cell Cardiol [Internet]. 2020;144:47-53. Disponible en: http://doi.org/10.1016/j.yjmcc.2020.04.031

24. Xu Z, Shi L, Wang Y, Zhang J, Huang L, Zhang C, et al. Pathological findings of Covid-19 associated with acute respiratory distress syndrome. Lancet Respir Med [Internet]. 2020;8(4):420422. Disponible en: http://doi.org/10.1016/S2213-2600(20)30076-X

25. Suess C, Hausmann R. Gross and histopathological pulmonary findings in a Covid-19 associated death during self-isolation. Int J Legal Med [Internet]. 2020;134(4):1285-1290. Disponible en: http://doi.org/10.1007/s00414-020-02319-8

26. Ackermann M, Verleden SE, Kuehnel M, Haverich A, Welte T, Laenger F, et al. Pulmonary Vascular Endothelialitis, Thrombosis, and Angiogenesis in Covid-19. N Engl J Med [Internet]. 2020;383(2):120-128. Disponible en: http://www.doi.org/10.1056/NEJMoa2015432h

27. You J, Zhang L, Ni-jia-Ti M, Zhang J, Hu F, Chen L, et al. Anormal pulmonary function and residual CT abnormalities in rehabilitating Covid-19 patients after discharge. J Infect [Internet]. 2020;81(2):e150-e152. Disponible en: http://doi.org/10.1016/j.jinf.2020.06.003

28. Shi H, Han X, Jiang N, Cao Y, Alwalid O, Gu J, et al. Radiological findings from 81 patients with Covid-19 pneumonia in Wuhan, China: a descriptive study. Lancet Infect Dis [Internet]. 2020;20(4):425-434. Disponible en: http://doi.org/10.1016/S1473-3099(20)30086-4

29. Mason RJ. Pathogenesis of COVID from a cell biology perspective. Eur Resp J. 2020;55(4):2000607. Disponible en: http://doi.org/10.1183/13993003.00607-2020

30. Xie P, Ma W, Tang H, Liu D. Severe Covid-19: A Review of Recent Progress With a Look Toward the Future. Front Public Health [Internet]. 2020;8:189. Disponible en: http://doi.org/10.3389/ fpubh.2020.00189

31. George PM, Wells AU, Jenkins RG. Pulmonary fibrosis and Covid-19: the potential role for antifibrotic therapy. Lancet Respir Med [Internet]. 2020;8(8):807-815. Disponible en: http://doi.org/10.1016/ S2213-2600(20)30225-3

32. Severin R, Arena R, Lavie CJ, Bond S, Phillips SA. Respiratory Muscle Performance Screening for Infectious Disease Management Following Covid-19: A Highly Pressurized Situation. Am J Med. 2020;133(9):1025-1032. Disponible en: http://doi.org/10.1016/j.amjmed.2020.04.003 
33. Culp WC. Coronavirus Disease 2019: In-Home Isolation Room Construction. A\&A Pract [Internet]. 2020;14(6):e01218. Available from: http://journals.lww.com/10.1213/ XAA.0000000000001218. Disponible en: http://doi.org/10.1213/XAA.0000000000001218

34. Lai CC, Liu YH, Wang CY, Wang YH, Hsueh S-C, Yen M-Y, et al. Asymptomatic carrier state, acute respiratory disease, and pneumonia due to severe acute respiratory syndrome coronavirus 2 (Sars-CoV-2): Facts and myths. J Microbiol Immunol Infect [Internet]. 2020;53(3):404-412. Disponible en: http://doi.org/10.1016/j.jmii.2020.02.012

35. Nishiura H, Kobayashi T, Miyama T, Suzuki A, Jung S, Hayashi K, et al. Estimation of the asymptomatic ratio of novel coronavirus infections (Covid-19). Int J Infect Dis [Internet]. 2020 May;94:154-5. Disponible en: https://doi.org/10.1016/j.ijid.2020.03.020

36. Centers for Disease Control and Prevention [CDC]. Discontinuation of Transmission-Based Precautions and Disposition of Patients with Covid-19 in Healthcare Settings (Interim Guidance) [Internet]. 2020 [citado 2020 junio 15]. Disponible en: https://www.cdc.gov/coronavirus/2019-ncov/hcp/disposition-hospitalized-patients.html

37. Aytür YK, Köseoglu BF, Taşkıran OO, Ordu-Gökkaya NK, Delialioğ SU, Tur BS, et al. Pulmonary rehabilitation principles in Sars-COV-2 infection (Covid-19): A guideline for the acute and subacute rehabilitation. Turkish J Phys Med Rehabil [Internet]. 2020;66(2):104-120. Disponible en: http://doi.org/10.5606/tftrd.2020.6444h

38. Zhao H-M, Xie Y-X, Wang C. Recommendations for respiratory rehabilitation in adults with coronavirus disease 2019. Chin Med J (Engl) [Internet]. 2020;133(13):1595-15602. Disponible en: http://doi.org/10.1097/CM9.0000000000000848

39. Ahmed H, Patel K, Greenwood D, Halpin S, Lewthwaite P, Salawu A, et al. Long-term clinical outcomes in survivors of severe acute respiratory syndrome and Middle East respiratory syndrome coronavirus outbreaks after hospitalisation or ICU admission: A systematic review and metaanalysis. J Rehabil Med [Internet]. 2020;52(5):jrm00063.

Disponible en: http://doi.org/10.2340/16501977-2694

40. Wu KK, Chan SK, Ma TM. Posttraumatic Stress after SARS. Emerg Infect Dis [Internet]. 2005;11(8):1297-1300. Disponible en: http://doi.org/10.3201/eid1108.041083

41. Rogers JP, Chesney E, Oliver D, Pollak TA, McGuire P, Fusar-Poli P, et al. Psychiatric and neuropsychiatric presentations associated with severe coronavirus infections: a systematic review and meta-analysis with comparison to the Covid-19 pandemic. The Lancet Psychiatry [Internet]. 2020;7(7):611-627. Disponible en: http://doi.org/10.1016/S2215-0366(20)30203-0

42. Ozamiz-Etxebarria N, Dosil-Santamaria M, Picaza-Gorrochategui M, Idoiaga-Mondragon N. Niveles de estrés, ansiedad y depresión en la primera fase del brote del Covid-19 en una muestra recogida en el norte de España. Cad Saude Publica [Internet]. 2020;36(4):e00054020. Disponible en: http://doi.org/10.1590/0102-311x00054020

43. Spruit MA, Singh SJ, Garvey C, ZuWallack R, Nici L, Rochester C, et al. An Official American Thoracic Society/European Respiratory Society Statement: Key Concepts and Advances in Pulmonary Rehabilitation. Am J Respir Crit Care Med [Internet]. 2013;188(8):e13-e64. Disponible en: http://doi.org/10.1164/rccm.201309-1634ST

44. Barker-Davies RM, O'Sullivan O, Senaratne KPP, Baker P, Cranley M, Dharm-Datta S, et al. The Stanford Hall consensus statement for post-Covid-19 rehabilitation. Br J Sports Med [Internet]. 2020;54(16):949-959. Disponible en: http://doi.org/10.1136/bjsports-2020-102596

45. Li J. Rehabilitation management of patients with Covid-19: lessons learned from the first experience in China. Eur J Phys Rehabil Med [Internet]. 2020;56(3):335-338. Disponible en: https://doi.org/10.23736/s1973-9087.20.06292-9 
46. Sheehy LM. Considerations for Postacute Rehabilitation for Survivors of Covid-19. JMIR Public Health Surveill [Internet]. 2020;6(2):e19462. Disponible en: https://doi.org/10.2196/19462

47. Yang LL, Yang T. Pulmonary Rehabilitation for Patients with Coronavirus Disease 2019 (COVID19). Chronic Dis Transl Med [Internet]. 2020;6(2):79-86. Disponible en: https://doi.org/10.1016/j.cdtm.2020.05.002

48. Mohamed AA, Alawna M. Role of increasing the aerobic capacity on improving the function of immune and respiratory systems in patients with coronavirus (Covid-19): A review. Diabetes Metab Syndr. 2020;14(4):489-496. Disponible en: http://doi.org/10.1016/j.dsx.2020.04.038

49. Vitacca M, Carone M, Clini EM, Paneroni M, Lazzeri M, Lanza A, et al. Joint Statement on the Role of Respiratory Rehabilitation in the Covid-19 Crisis: The Italian Position Paper. Respiration [Internet]. 2020;99(6):493-499. Disponible en: http://doi.org/10.1159/000508399

50. Liu K, Zhang W, Yang Y, Zhang J, Li Y, Chen Y. Respiratory rehabilitation in elderly patients with Covid-19: A randomized controlled study. Complement Ther Clin Pract [Internet]. 2020;39:101166. Disponible en: https://doi.org/10.1016/j.ctcp.2020.101166

51. Bryant MS, Fedson SE, Sharafkhaneh A. Using Telehealth Cardiopulmonary Rehabilitation during the Covid-19 Pandemic. J Med Syst [Internet]. 2020;44(7):125. Disponible en: http://doi.org/10.1007/s10916-020-01593-8

52. Iannaccone S, Castellazzi P, Tettamanti A, Houdayer E, Brugliera L, de Blasio F, et al. Role of Rehabilitation Department for Adult Covid-19 Patients: the Experience of the San Raffaele Hospital of Milan. Arch Phys Med Rehabil [Internet]. 2020;101(98):1656-1661. Disponible en: http://doi.org/10.1016/j.apmr.2020.05.015

53. Raj VS. Covid-19?: We All Have a Role. Arch Phys Med Rehabil [Internet]. 2020;101(8):1471. Disponible en: https://doi.org/10.1016/j.apmr.2020.04.014

54. Batawi S, Tarazan N, Al-Raddadi R, Al Qasim E, Sindi A, Al Johni S, et al. Quality of life reported by survivors after hospitalization for Middle East respiratory syndrome (Mers). Health Qual Life Outcomes. 2019;17(1):101. Disponible en: https://doi.org/10.1186/s12955-019-1165-2

55. Guo L, Han Y, Li J, Chen Q, Ren Y, Wu Q, et al. Long-term outcomes in patients with severe acute respiratory syndrome treated with oseltamivir: a 12-year longitudinal study. Int J Clin Exp Med. 2019;12(10):12464-12471. Disponible en: http://www.ijcem.com/files/ijcem0074733.pdf

56. Rivera G, Torres R, Fregonezi G, Vilaró J, Puppo H. Challenge for Rehabilitation After Hospitalization for Covid-19. Arch Phys Med Rehabil [Internet]. 2020;101(8):1470-1471. Disponible en: http://doi.org/10.1016/j.apmr.2020.04.013

57. McCormack MC, Kaminsky DA. Pulmonary Function Laboratories: Advice Regarding COVID19 [Internet]. ATS: Disease Related Resources. 2020 [citado 2020 junio 15]. Disponible en: https://www.thoracic.org/professionals/clinical-resources/disease-related-resources/pulmonaryfunction-laboratories.php 